\title{
Blood Lead Levels and Major Depressive Disorder, Panic Disorder, and Generalized Anxiety Disorder in US Young Adults
}

\section{Citation}

Bouchard, Maryse F., David C. Bellinger, Jennifer Weuve, Julia Matthews-Bellinger, Stephen E. Gilman, Robert O. Wright, Joel Schwartz, and Marc G. Weisskopf. 2009. "Blood Lead Levels and Major Depressive Disorder, Panic Disorder, and Generalized Anxiety Disorder in US Young Adults." Archives of General Psychiatry 66 (12) (December 1): 1313. doi:10.1001/ archgenpsychiatry.2009.164.

\section{Published Version}

doi:10.1001/archgenpsychiatry.2009.164

\section{Permanent link}

http://nrs.harvard.edu/urn-3:HUL.InstRepos:26854118

\section{Terms of Use}

This article was downloaded from Harvard University's DASH repository, and is made available under the terms and conditions applicable to Other Posted Material, as set forth at http:// nrs.harvard.edu/urn-3:HUL.InstRepos:dash.current.terms-of-use\#LAA

\section{Share Your Story}

The Harvard community has made this article openly available.

Please share how this access benefits you. Submit a story.

Accessibility 


\title{
Blood lead levels and major depressive disorder, panic disorder, and generalized anxiety disorder in U.S. young adults
}

\author{
Maryse Bouchard, PhD, MSc, \\ Département de santé environnementale et santé au travail, Université de Montréal, Québec, \\ Canada
}

David C. Bellinger, PhD, MSc,

Departments of Neurology, and Environmental Health, Harvard Medical School, Harvard School of Public Health, Children's Hospital, Boston, MA, USA

Jennifer Weuve, MPH, ScD,

Rush Institute for Healthy Aging, Rush University Medical Center, Chicago, IL, USA. Department of Environmental Health, Harvard School of Public Health, Boston, MA, USA

Julia Matthews-Bellinger, PhD, MD,

Department of Psychiatry, UMass Medical School, Worcester, MA, USA

Stephen E. Gilman, ScD,

Departments of Society, Human Development, and Health, and Epidemiology, Harvard School of Public Health, Boston, MA, USA

Robert O. Wright, MD MPH,

Departments of Pediatrics, Harvard Medical School, Children's Hospital, Boston, and Environmental Health, Harvard School of Public Health, Boston, MA, USA

Joel Schwartz, PhD, and

Departments of Environmental Health and Epidemiology, Harvard School of Public Health, Boston, MA, USA

\section{Marc G. Weisskopf, PhD}

Departments of Environmental Health, and Epidemiology, Harvard School of Public Health. Channing Laboratory, Department of Medicine, Harvard Medical School and Brigham and Women's Hospital, Boston, MA, USA

\section{Abstract}

Context-Lead is a ubiquitous neurotoxicant, and adverse cognitive and behavioral effects are well documented in children and occupationally exposed adults but not in adults with low environmental exposure.

Objective-To investigate the association of current blood lead levels with three common psychiatric disorders, major depression, panic, and generalized anxiety, among young adults.

Design-Cross-sectional epidemiologic survey.

Setting-Representative sample of non-institutionalized United States adults.

Request for reprint: Maryse Bouchard, Département de santé environnementale et santé au travail, Université de Montréal, C.P. 6128 Succursale Centre-Ville, Montréal (Qc) H3C 3J7, Canada.

The authors declare no financial interest. 
Participants-A total of 1,987 respondents of age 20-39 years to the National Health and Nutrition Examination Survey conducted from 1999 to 2004.

Main Outcome Measures-Twelve-month DSM-IV criteria-based diagnoses of major depressive disorder, panic disorder, and generalized anxiety disorder assessed by the Composite International Diagnostic Interview.

Results-Mean blood lead level was $1.61 \mu \mathrm{g} / \mathrm{dL}$ (SD 1.72, range 0.3-37.3 $\mu \mathrm{g} / \mathrm{dL}$ ). Increasing blood lead level was associated with higher odds of major depression ( $\mathrm{p}$ for trend 0.05 ) and panic disorder ( $\mathrm{p}$ for trend 0.02 ), but not generalized anxiety disorder ( $\mathrm{p}$ for trend 0.75 ), after adjustment for sex, age, race/ethnicity, education, and poverty-income ratio. Persons with blood lead level in the highest quintile had 2.3 times the odds of major depressive disorder (95\% CI $1.13-4.75$ ) and 4.9 times the odds of panic disorder (95\% CI $1.32-18.48$ ) as those in the lowest quintile. Cigarette smoking was associated with higher blood lead level and the outcomes, but models excluding current smokers also resulted in significantly increased odds for major depression ( $\mathrm{p}$ for trend 0.03) and panic disorder ( $\mathrm{p}$ for trend 0.01) with higher blood lead quintile.

Conclusions-In this sample of young adults with low levels of lead exposure, higher blood lead was associated with increased odds of major depression and panic disorder. Exposure to lead at levels generally considered safe could result in adverse mental health outcomes.

\section{INTRODUCTION}

Lead is a well known neurotoxicant that is ubiquitous in the environment, found in air, soil, dust, and water. Blood lead levels measured in the National Health and Nutrition Examination Survey (NHANES) program have been a cornerstone of lead exposure surveillance in the United States since the early 1970 s. $^{1}$ The data show a dramatic decline in average blood lead levels since $1980,{ }^{2}$ due in large part to the removal of lead from gasoline. However, several sources of exposure remain, such as paint, industrial processes, water contaminated by corroding pipes or solder, mining, pottery, and folk medicine. Adverse effects of lead have been reported for different organ systems, most notably the nervous system, ${ }^{3}$ but also cardiovascular,,${ }^{4}$ and renal systems. ${ }^{6}$

Research on neurotoxic effects of low level of exposure to lead has focused on in utero or early childhood. ${ }^{7}$ In adult populations, the neurotoxic effects of lead have been studied mainly in the context of occupational exposures, with levels of exposure orders of magnitude greater than that experienced by the general population. Lead-exposed workers in foundries, battery plants, or lead smelter were reported to suffer from cognitive and neuromotor deficits, as well as mood disorders such as anxiety, hostility, and depressive states ${ }^{8-13}$ Nearly all of the participants in these investigations were males, with average blood lead levels as high as $40 \mu \mathrm{g} / \mathrm{dL}$.

Few studies have addressed nervous system effects of lead exposure at low levels commonly encountered in the general adult population. In 1999-2002, the average blood lead levels in 20 to 59 years old adults living in the United States was $1.5 \mu \mathrm{g} / \mathrm{dL}$ (geometric mean). ${ }^{14}$ One study in the general adult population suggests that lead exposure might adversely affect emotional regulation. Higher blood and bone lead levels in 526 men living in or near Boston, Massachusetts, was associated with a higher degree of anxiety, phobic anxiety, and depression on a symptoms questionnaire after adjusting for covariates. ${ }^{15}$ The association between lead and adverse neuropsychiatric symptoms was greater among delta aminolevulinic acid dehydratase (ALAD) 1-1 carriers than 1-2/2-2 carriers, suggesting possible effect modification by genotype. ${ }^{16}$ The blood lead level in this sample of older men (mean age 63 years) averaged $6.3 \mu \mathrm{g} / \mathrm{dL}$, and the assessment of psychopathology relied on 
self-reported symptoms rather than psychiatric disorders defined by standard diagnostic criteria.

Depression and anxiety disorders are common forms of psychopathology in the general adult population, causing substantial morbidity. Most research on environmental risk factors has focused on the social environment. Investigation of other environmental risk factors could contribute to our understanding of their etiology. Our aim in the present study was to assess the possible role of exposure to lead in adverse mental health outcomes among a more broadly distributed and younger population. We used data from the National Health and Nutrition Examination Survey (NHANES), for years 1999 to 2004, to investigate the relation between blood lead levels and the odds of major depressive disorder, panic disorder, and generalized anxiety disorder, in a sample representative of the United States population aged 20 to 39 years.

\section{METHODS}

\section{Study Design and Population}

The NHANES is a population-based health survey of non-institutionalized US residents conducted by the National Center for Health Statistics of the Center for Disease Control and Prevention (CDC). The NHANES uses a complex, multistage probability sampling design, with oversampling of adolescents 12-19 years of age, adults $\geq 60$ years of age, low-income persons, Mexican Americans, and non-Hispanic blacks. All participants completed household surveys conducted by trained study staff, which included questions about demographics and health history. The study protocol also included standardized medical examinations at mobile centers that included a private interview and collection of a blood sample. The study protocol is described in detail elsewhere. ${ }^{17}$

The World Health Organization Composite International Diagnostic Interview (CIDI) ${ }^{18}$ was administered to a random sub-sample of the participants composed of $50 \%$ of those aged 20 to 39 years. The CIDI was administered in English or Spanish. All interviews were conducted directly with the respondents during a private interview; persons requiring proxies were ineligible (i.e. non-English and non-Spanish speakers).

Our study included the 1,987 individuals who had available data on CIDI diagnoses of major depressive disorder, panic disorder, generalized anxiety disorder, blood lead level, and all covariates.

\section{Measures}

Psychiatric Outcomes-The CIDI is a fully structured diagnostic interview used to assess psychiatric disorders following criteria defined in the fourth edition of the American Psychiatric Association's Diagnostic and Statistical Manual of Mental Disorders (DSM-IV). 19 Three diagnostic modules were administered: i) Major Depressive Disorder, ii) Panic Disorder, and iii) Generalized Anxiety Disorder. The CIDI questions address the DSM-IV criteria for each of the three disorders and a diagnosis is established based on the answers. Only disorders present during the previous 12 months were identified in this survey.

Major depressive disorder is defined as one or more major depressive episodes, characterized by at least two weeks of depressed mood or loss of interest, accompanied by at least four additional symptoms of depression among: significant appetite/weight change; insomnia or hypersomnia; psychomotor agitation or retardation; fatigue or loss of energy; diminished ability to think, or concentrate, or indecisiveness; recurrent thoughts of death, suicidal ideation, plan, or attempts. The symptoms must cause significant distress or impairment, and are not the result of bereavement. Panic disorder is defined by intense 
periods of fear of discomfort, i.e. panic attacks, that are recurrent and occur unexpectedly. A panic attack is identified when at least four symptoms were present among: heart racing; sweating; shaking; shortness of breath; feel choked; chest pain; nausea; dizziness; feel unreal/situation is unreal; afraid to lose control; hot flash; numbness. A positive diagnosis is established if four or more panic attacks occurred, and at least one attack caused concern, worry, or behaviour change during one month or more. Generalized anxiety disorder is defined by excessive anxiety and worry that is difficult to control, with at least three symptoms of anxiety, among: unusual fatigue; trouble sleeping; trouble concentrating; irritability; feeling tensed, sore, or muscles ache. The anxiety must cause clinically significant distress or impairment. For all three disorders, symptoms must not be due to the direct physiological effects of a substance, or another medical condition.

Participants completed the CIDI during a private interview with trained interviewers. An automated version of the CIDI (version 2.1) was used to facilitate the interview process and data management. ${ }^{18}$ The CIDI addresses each symptom listed above, the context in which it occurred and the exterior factors possibly explaining them, and the distress associated with them in order to establish the diagnoses based on the DSM-IV criteria. CIDI responses are evaluated using a computer algorithm assessing each criterion, and criteria are combined into diagnoses. The diagnoses are designated as part of NHANES data-processing and the dichotomous diagnosis variables-i.e., yes or no for a diagnosis in the last 12 months - were in the NHANES downloaded datasets. These variables are the outcomes in the present study.

The CIDI has been widely used in research and population surveys. ${ }^{20-22}$ It can be administered by lay interviewers with excellent reliability, does not require outside informants or medical records, and does not assume the presence of a current disorder. ${ }^{18} \mathrm{In}$ a validity study, CIDI diagnoses were compared with diagnoses from the Structured Clinical Interview for DSM-IV (SCID), and high level of concordance was observed. ${ }^{23}$ Specifically, $84 \%$ of cases of anxiety disorder and $70 \%$ of cases of mood disorder identified in the clinical interview were also identified by the CIDI. CIDI lifetime prevalence estimates were generally lower than SCID estimates. The concordance in SCID and CIDI is likely to be constrained because the SCID itself has only moderate reliability. Also, the difference in the mode of administration, i.e. telephone interview for SCID and in-person interview for CIDI, could contribute to discordant diagnoses.

Blood lead-Whole blood specimens were processed, stored, and shipped to the Division of Laboratory Sciences, National Center for Environmental Health, and Centers for Disease Control and Prevention for analysis. Vials were stored at $-20^{\circ} \mathrm{C}$ until they were shipped. For samples collected in 1999 to 2002, blood lead concentration was determined by graphite furnace atomic absorption spectrophotometry and the limit of detection (LOD) was $0.3 \mu \mathrm{g} /$ dL. ${ }^{24,}{ }^{25}$ For samples collected in 2003 and 2004, whole blood lead was determined by inductively coupled plasma mass spectrometry and the LOD was $0.2 \mu \mathrm{g} / \mathrm{L}$. The NHANES quality assurance and quality control protocols meet the 1988 Clinical Laboratory Improvement Act mandates (see CDC for a detailed description). ${ }^{26}$

Other Variables-We included the following variables in the analyses because of their known associations with lead exposure and/or mental health status: sex, age, race/ethnicity, education, poverty-income ratio (PIR). Non-Hispanic African Americans have higher rates of depression than non-Hispanic white persons. ${ }^{27}$ Women have higher rates of depressive and anxiety disorders, ${ }^{22}$ as do individuals with less education. ${ }^{28}$ The prevalence of several disorders is higher among those with lower socio-economic status, ${ }^{22}$ which here was assessed by the PIR, a parameter comparing the self-reported family income to the United States Census-based poverty threshold value for each calendar year adjusted for inflation and the age of the family reference person. PIR was coded into four categories to reflect the 
current standards used in government-financed welfare programs (the lowest category, $\leq 1.0$, corresponds to the poorest group). Finally, smoking is strongly associated with depression and anxiety disorders. ${ }^{29}$ Past and current use of tobacco products was assessed by questionnaire, and cotinine levels were measured in the serum to further identify active smokers (based on the $10 \mathrm{ng} / \mathrm{mL}$ cut-off commonly used). ${ }^{30} \mathrm{~A}$ total of 628 persons were considered current smokers; 526 persons based on the questionnaire and an additional 102 persons based on serum cotinine. Lead exposure also differs with respect to sex (higher in men), race/ethnicity (higher in African Americans), education (higher with lower educational attainment), socio-economic status (higher in lower socio-economic strata), and smoking (higher in smokers). ${ }^{31,} 32$

Statistical Analyses-We used the Complex Samples module of SPSS 17.0 (SPSS Inc., Chicago, IL) to obtain effect estimates and their confidence intervals, accounting for the multistage probability sampling design of the NHANES. The NHANES provides sample weights to generate population prevalence estimates, adjusting for the over-sampling of certain population subgroups and accounting for non-response and non-coverage. ${ }^{33}$ For estimates of outcome prevalence and odds ratio, we used the special examination sample weights for the subsample eligible to be administered the CIDI, computing 6-year weights (1999-2004) using the method recommended by the CDC. ${ }^{34}$

To reduce the influence of extreme values on our analyses, we analyzed blood lead levels in quintiles (lowest: $0.2-0.7 \mu \mathrm{g} / \mathrm{dL} ; 2^{\text {nd }}: 0.71-1.0 \mu \mathrm{g} / \mathrm{dL} ; 3^{\text {rd }}: 1.01-1.4 \mu \mathrm{g} / \mathrm{dL} ; 4^{\text {th }}: 1.41-$ $2.1 \mu \mathrm{g} / \mathrm{L}$; highest: $\geq 2.11 \mu \mathrm{g} / \mathrm{dL}$ ). Thirty-three participants (1.6\%) had blood lead levels lower than the limits of detection. We fit multivariable-adjusted logistic regression models to estimate the prevalence odds ratios (ORs) and 95\% confidence intervals (CI) of major depressive disorder, panic disorder, and generalized anxiety disorder across increasing blood lead level quintile, relative to the lowest quintile (i.e., the referent). To assess the linear trend in these associations, we fit models using a term created by assigning to each individual the median value of his or her blood lead quintile. All models were adjusted for : sex, age (2024 y, 25-29 y, $30-34$ y, 35-39 y), race/ethnicity (Non-Hispanic White, Mexican American, Non-Hispanic Black, and other race or multiracial), education (less than high school, high school diploma, more than high school), and PIR (<1.0, 1.0 - 1.85, 1.85 - 3.0, > 3.0). As an alternative modeling strategy, we also fitted logistic regression models using $\log _{10}$-transformed blood lead values. The presence of a possible time trend was assessed by adding a dummy variable for the wave of data collection years $(1=1999-2000,2=2001-$ 2002 , and $3=2003-2004)$ in the models. Finally, we also used sub-population analyses to obtain results stratified by sex. We used $p<0.05$ as the level of significance.

\section{RESULTS}

Descriptive statistics are presented in Table 1. The study population included more women than men, but once weighted, the observations accounted for an equal representation of men and women. The age distribution was fairly uniform and spanned between 20 and 39 years. The numbers of persons meeting the 12-months DSM-IV criteria were $134(6.7 \%)$ for major depressive disorder, 44 for panic disorder $(2.2 \%)$, and 47 (2.4\%) for generalized anxiety disorder (Table 2). The corresponding population prevalence estimates, determined after applying the sample weights, were $7.8 \%, 2.6 \%$, and $3.0 \%$. There were no significant differences in blood lead levels, age, sex, race/ethnicity, education, PIR, or smoking between those to whom the CIDI was administered and those to whom it was not $(\mathrm{p}>0.1)$.

The geometric mean blood lead level was $1.24 \mu \mathrm{g} / \mathrm{dL}$ (geometric standard deviation [SD] 1.96). The arithmetic mean was $1.61 \mu \mathrm{g} / \mathrm{dL}$ (SD 1.72), and values ranged from 0.3 to 37.3 $\mu \mathrm{g} / \mathrm{dL} ; 13$ values $(0.7 \%)$ exceeded $10 \mu \mathrm{g} / \mathrm{dL}$, and 4 values $(0.2 \%)$ exceeded $15 \mu \mathrm{g} / \mathrm{dL}$. In 
multivariable-adjusted analyses, significantly higher blood lead levels were observed with the following characteristics: being a man, older age, Mexican Americans, lower education, and current smoking. Blood lead levels were also higher in the poorest group (PIR < 1.0), although differences by PIR groups were not statistically significant $(\mathrm{p}=0.80)$.

Logistic regression analyses, adjusting for age, sex, race/ethnicity, education, and PIR, showed that higher blood lead quintile was significantly associated with higher odds of meeting the DSM-IV criteria for major depression $(\mathrm{p}$ for trend $=0.05)$ and panic disorder $(\mathrm{p}$ for trend $=0.02)$, but not generalized anxiety disorder $(\mathrm{p}=0.78)$ (Table 3 [Model A]). Persons with blood lead levels in the highest quintile had 2.3 times the odds of major depressive disorder (95\% CI $1.13-4.75$ ) and nearly five times the odds of panic disorder (95\% CI $1.32-18.48)$ as those in the lowest quintile. Sex and race/ethnicity were significantly associated with the risk of disorders (both at $\mathrm{p}<0.01$ ), but not age, education, or PIR ( $p>0.3$ for each). Mexican Americans had the lowest rates of major depressive disorder and panic disorder, but the highest blood lead levels. Men had lower rates of disorders but higher blood lead levels than women.

We saw little difference by sex in the associations of blood lead levels with major depressive disorder, and an interaction term added to the logistic regression model was not significant $(\mathrm{p}=0.76)$. There were too few cases of panic disorder among men to analyze them separately, but the association among women only was similar to the combined results.

To evaluate possible cohort effects we added a term for years of data collection to our models, but this term was not significant $(\mathrm{p}=0.99$ for major depression, $\mathrm{p}=0.53$ for panic disorder, and $\mathrm{p}=0.54$ for generalized anxiety disorder) and did not appreciably change the associations with blood lead.

We also evaluated the odds of each of the three disorders with respect to blood lead levels on a continuous scale ( $\log _{10}$ transformed) and this resulted in findings similar to the previous trend analyses, with higher blood lead being associated with increased odds of major depression (OR for each doubling of blood lead 1.19; 95\% CI [0.93-1.53]; $\mathrm{p}=0.16$ ) and panic disorder (OR for each doubling of blood lead 1.44; 95\% CI [1.02-2.03]; $\mathrm{p}=$ 0.04 ), but not generalized anxiety disorder (OR for each doubling of blood lead $1.11 ; 95 \%$ CI [0.76-1.63]; $\mathrm{p}=0.56)$.

Because current smoking is related to blood lead level as well as psychopathology status, we conducted sensitivity analyses excluding the 628 current smokers (Table 3 [Model B]). For major depressive disorder, this resulted in ORs slightly higher than those obtained when including these individuals, and a significant trend $(p=0.03)$ for increasing odds across increasing blood lead quintile. Increasing quintile of blood lead level was also significantly associated with higher odds of panic disorder ( $\mathrm{p}$-value for trend $=0.01$ ). The OR for the highest quintile of blood lead was substantially higher than in Model A; however its wide 95\% CI was due to the small number of cases in this analysis ( $\mathrm{n}=17)$.

Exclusion of individuals with blood lead $\geq 10 \mu \mathrm{g} / \mathrm{dL}$ ( $\mathrm{n}=13$ ) did not affect the results, with changes only to the second decimal of the estimates. The results were only minimally affected by the exclusion of pregnant women and women whose pregnancy status could not be ascertained $(\mathrm{n}=299)$, with estimates within $10 \%$ of those for Model A, and similar p-fortrend values (major depression's $\mathrm{p}=0.05$, panic disorder's $\mathrm{p}=0.02$, and generalized anxiety disorder's $\mathrm{p}=0.50$ ).

Many individuals met the criteria for more than one disorder, thus, we wanted to explore the specificity of the blood lead association for a single diagnosis. Among those with major depression, $6 \%$ also met the criteria for panic disorder, $10 \%$ for generalized anxiety 
disorder, and $7 \%$ for both. We conducted an analysis on the 104 cases of major depression with no co-morbid disorder, and the findings were similar to those conducted on all cases. The numbers of cases of panic disorder and generalized anxiety disorder with no comorbidity were too small ( $\mathrm{n}=24$ and 22 , respectively) to restrict the analytic sample to these cases only.

\section{DISCUSSION}

In the present study, we observed that increasing blood lead levels was associated with a significantly higher risk of major depression and panic disorder in young adults from the United States. Compared with persons with a blood lead level below $0.7 \mu \mathrm{g} / \mathrm{dL}$ (the lowest quintile of blood lead in our study population), those with a level greater than $2.1 \mu \mathrm{g} / \mathrm{dL}$ (the highest quintile) had a 2.3-fold increased risk of meeting the DSM-IV criteria for major depressive disorder, and 4.9-fold increased risk for panic disorder. After excluding current smokers, the elevation in risk was increased to 2.5 -fold for major depression and 8.2-fold for panic disorder. Although estimates of risk for specific quintiles were imprecise due the small number of cases, particularly for panic disorder, the trend analyses support the presence of significant increase in risk across blood lead levels. Likewise, models using a continuous parameter for blood lead level also support this conclusion.

These results support previously reported associations of mood and anxiety disorders with high occupational lead exposure, ${ }^{8-12}$ and less well documented association with lower environmental levels of exposure in older men. ${ }^{15}, 16$ Our findings extend these observations to the general United States population of younger adults. Women are at significantly increased risk of meeting the diagnostic criteria for major depression and anxiety disorders, an observation which is previously well documented. ${ }^{20}$ In exploratory analyses, we saw no evidence of differential association by sex for blood lead levels and odds for these disorders, but a larger sample would be necessary to carefully verify this hypothesis.

If lead exposure contributes to the etiology of these disorders, the mechanism of action could involve perturbation of neurochemistry, such as brain monoamine neurotransmission. Lead exposure is known to disrupt catecholaminergic systems, ${ }^{35-37}$ and depression and anxiety disorders are strongly associated with disturbances in these systems. ${ }^{38}$ Studies in animals show that chronic lead exposure can decrease serotoninergic activity in several brain regions including the nucleus accumbens, frontal cortex, and brainstem. ${ }^{37}$ In a study of patients with panic disorder, with or without depression, positron emission tomography revealed that the serotonin receptor type $1 \mathrm{~A}$ was reduced by nearly a third in the anterior and posterior cingulate, and raphe nuclei. ${ }^{39}$ Exposure to lead in predisposed individuals could trigger the development of the depression and panic disorder, increase their severity, or modify response to treatments. Investigations on how low lead exposure disrupts neurochemistry could provide insights in the mechanisms of depressive and anxious states.

Co-morbidity was observed in the present study, particularly for the two anxiety disorders with depression. When we conducted an analysis of major depressive disorder in which we excluded persons with major depressive disorder and another disorder, the findings were similar to those in which we included all persons, suggesting that the increased odds of major depressive disorder with higher blood lead level was not explained by the anxiety disorders.

One of the strengths of the present study is the use of structured diagnostic assessments of psychiatric disorders. ${ }^{18}$ The CIDI has been widely used in psychiatric research, and has a high degree of correspondance with clinical interviews. ${ }^{23}$ Also, the prevalence observed in the present study for the three conditions studied were very comparable to other national 
estimates ${ }^{20}$ i.e. major depressive disorder ( $7.8 \%$ versus $\left.6.7 \%\right)$, panic disorder $(2.6 \%$ versus $2.7 \%)$, and generalized anxiety disorder (3.0\% versus $3.1 \%)$. This suggests that the results of the present study can be generalized to the broader U.S. population.

The present study has several limitations, the most important being its cross-sectional design. Thus, we cannot rule out the possibility that major depression or panic disorder leads to behavioral changes that increase exposure to lead—except in the case of smoking, for which our sensitivity analysis among current non-smokers argues strongly against this. In addition, the mental health outcomes under study here are chronic conditions often associated with genetic predisposition in conjunction with chronic stressors. ${ }^{40}$ Therefore, in assessing the role of lead as a risk factor for mental health outcomes, it would have been desirable to have an indicator of long-term lead exposure, such as bone lead level, assessed prior to onset of psychopathology. Bone lead level has a clearance half-life of years to decades, depending on the bone type. ${ }^{41}$ In a previous study, both blood and patella bone lead were associated with a combined measure of anxiety, phobic anxiety, and depression symptoms. ${ }^{15}$ In the present study, lead was measured only in blood. The half-life of lead in blood after acute exposure is short, but blood lead concentration integrates lead released from bones and current external exposures. In settings where external exposures are low, lead released from bones can be the major contributor to blood lead. Thus, blood lead may be a reasonable marker of long-term exposure when the system is in equilibrium, with little variation in intake, clearance, or bone-blood partitioning. Situations in which this would not apply are occupational exposures, which might vary greatly in time, and osteoporosis, during which lead is released from the bone matrix to the blood at an increased rate following demineralization. ${ }^{42}$ In the present study, however, few individuals were likely to suffer from osteoporosis because of their young age (maximum 40 years). We could not exclude occupationally exposed individuals because of limited information on job exposures, but our exclusion of those with elevated blood lead levels would likely capture any current work-related lead exposure and did not alter the results.

As in any observational study, the associations in our study could be biased by uncontrolled confounders. We were, however, able to adjust for several important likely confounding factors, namely sex, age, race/ethnicity, education, and income. Furthermore, our sensitivity analyses excluding current smokers indicate that residual confounding by smoking does not explain the associations of blood lead and risk of psychopathology, but in fact may partly mask it.

Current blood lead levels in the United States population are lower than those in the mid- $20^{\text {th }}$ century, ${ }^{2}$ but they remain elevated from an evolutionary perspective, i.e., in relation to the natural lead levels prior to industrialization. ${ }^{43}$ Widespread lead pollution occurred only in relatively modern history as a result of anthropogenic activity. ${ }^{44}$ The finding of an association between blood lead level and major depressive disorder and panic disorder, despite the low levels and narrow range of observed lead levels, supports the contention that current lead exposures at low levels may have important effects on mental health. Since the current measurements of blood lead reflect in part lead sequestered in bone, the observed relations with increased odds for depression and panic disorder could also reflect latent effects of past exposures during critical developmental periods, which would be consistent with neurodevelopmental hypotheses of mood and anxiety disorders. ${ }^{45}$ If lead exposure contributes to the etiology of major depression and panic disorder, the continued efforts at reducing population exposures even beyond currently acceptable levels may decrease their incidence. 


\section{CONCLUSION}

The risks for major depressive disorder and panic disorder in young adults increased with higher blood lead levels. These findings suggest that lead neurotoxicity may be a contributing factor for adverse mental health outcomes, even at levels generally considered to pose low or no risk. Our findings, combined with recent report of adverse behavioral outcomes in children with similarly low blood lead levels, ${ }^{46,47}$ should underscore the need for considering ways to further reduce environmental lead exposures.

\section{Acknowledgments}

The Canadian Institutes for Health Research provided a fellowship for Dr. Bouchard. Dr. Weisskopf was supported by career development award K01 ES012653 from the National Institute of Environmental Health Sciences.

Funding: The Canadian Institutes for Health Research provided a fellowship for Dr. Bouchard. Dr. Weisskopf was supported by career development award K01 ES012653 from the National Institute of Environmental Health Sciences.

\section{REFERENCES}

1. Centers for Disease Control and Prevention (CDC). National Center for Health Statistics (NCHS). National Health and Nutrition Examination Survey Data. U.S. Department of Health and Human Services; Hyattsville, MD: [Accessed October 1, 2008]. http://www.cdc.gov/nchs/nhanes.htm

2. Pirkle JL, Brody DJ, Gunter EW, Kramer RA, Paschal DC, Flegal KM, Matte TD, The National Health and Nutrition Examination Surveys (NHANES). The decline in blood lead levels in the United States. Jama 1994;272(4):284-291. [PubMed: 8028141]

3. Schwartz BS, Stewart WF, Bolla KI, Simon PD, Bandeen-Roche K, Gordon PB, Links JM, Todd AC. Past adult lead exposure is associated with longitudinal decline in cognitive function. Neurology 2000;55(8):1144-1150. [PubMed: 11071492]

4. Glenn BS, Bandeen-Roche K, Lee BK, Weaver VM, Todd AC, Schwartz BS. Changes in systolic blood pressure associated with lead in blood and bone. Epidemiology 2006;17(5):538-544. [PubMed: 16906055]

5. Lee BK, Lee GS, Stewart WF, Ahn KD, Simon D, Kelsey KT, Todd AC, Schwartz BS. Associations of blood pressure and hypertension with lead dose measures and polymorphisms in the vitamin D receptor and delta-aminolevulinic acid dehydratase genes. Environ Health Perspect 2001;109(4):383-389. [PubMed: 11335187]

6. Weaver VM, Jaar BG, Schwartz BS, Todd AC, Ahn KD, Lee SS, Wen J, Parsons PJ, Lee BK. Associations among lead dose biomarkers, uric acid, and renal function in Korean lead workers. Environ Health Perspect 2005;113(1):36-42. [PubMed: 15626645]

7. Lanphear BP, Hornung R, Khoury J, Yolton K, Baghurst P, Bellinger DC, Canfield RL, Dietrich KN, Bornschein R, Greene T, Rothenberg SJ, Needleman HL, Schnaas L, Wasserman G, Graziano J, Roberts R. Low-level environmental lead exposure and children's intellectual function: an international pooled analysis. Environ Health Perspect 2005;113(7):894-899. [PubMed: 16002379]

8. Lilis R, Fischbein A, Eisinger J, Blumberg WE, Diamond S, Anderson HA, Rom W, Rice C, Sarkozi L, Kon S, Selikoff IJ. Prevalence of lead disease among secondary lead smelter workers and biological indicators of lead exposure. Environ Res 1977;14(2):255-285. [PubMed: 269801]

9. Baker EL, Feldman RG, White RA, Harley JP, Niles CA, Dinse GE, Berkey CS. Occupational lead neurotoxicity: a behavioural and electrophysiological evaluation. Study design and year one results. Br J Ind Med 1984;41(3):352-361. [PubMed: 6743583]

10. Baker EL, White RF, Pothier LJ, Berkey CS, Dinse GE, Travers PH, Harley JP, Feldman RG. Occupational lead neurotoxicity: improvement in behavioural effects after reduction of exposure. Br J Ind Med 1985;42(8):507-516. [PubMed: 4016002]

11. Parkinson DK, Ryan C, Bromet EJ, Connell MM. A psychiatric epidemiologic study of occupational lead exposure. Am J Epidemiol 1986;123(2):261-269. [PubMed: 3946375] 
12. Maizlish NA, Parra G, Feo O. Neurobehavioural evaluation of Venezuelan workers exposed to inorganic lead. Occup Environ Med 1995;52(6):408-414. [PubMed: 7627319]

13. Schwartz BS, Lee BK, Bandeen-Roche K, Stewart W, Bolla K, Links J, Weaver V, Todd A. Occupational lead exposure and longitudinal decline in neurobehavioral test scores. Epidemiology 2005;16(1):106-113. [PubMed: 15613953]

14. ATSDR. Toxicological profile for lead. [Accessed Jan 11, 2009]. http://www.atsdr.cdc.gov/toxprofiles/tp13.pdf

15. Rhodes D, Spiro A 3rd, Aro A, Hu H. Relationship of bone and blood lead levels to psychiatric symptoms: the normative aging study. J Occup Environ Med 2003;45(11):1144-1151. [PubMed: 14610395]

16. Rajan P, Kelsey KT, Schwartz JD, Bellinger DC, Weuve J, Sparrow D, Spiro A 3rd, Smith TJ, Nie $\mathrm{H}, \mathrm{Hu} \mathrm{H}$, Wright RO. Lead burden and psychiatric symptoms and the modifying influence of the delta-aminolevulinic acid dehydratase (ALAD) polymorphism: the VA Normative Aging Study. Am J Epidemiol 2007;166(12):1400-1408. [PubMed: 17823382]

17. National Center for Health Statistics (NCHS). National Health and Nutrition Examination Survey. [Accessed December 18, 2008]. http://www.cdc.gov/nchs/nhanes.htm

18. Kessler RC, Ustun TB. The World Mental Health (WMH) Survey Initiative Version of the World Health Organization (WHO) Composite International Diagnostic Interview (CIDI). Int J Methods Psychiatr Res 2004;13(2):93-121. [PubMed: 15297906]

19. American Psychiatric Association. Diagnostic and statistical manual of mental disorders: DSM-IV. 4th ed.. American Psychiatric Association; Washington, DC: 1994.

20. Kessler RC, Chiu WT, Demler O, Merikangas KR, Walters EE. Prevalence, severity, and comorbidity of 12-month DSM-IV disorders in the National Comorbidity Survey Replication. Arch Gen Psychiatry 2005;62(6):617-627. [PubMed: 15939839]

21. Kessler RC, Crum RM, Warner LA, Nelson CB, Schulenberg J, Anthony JC. Lifetime cooccurrence of DSM-III-R alcohol abuse and dependence with other psychiatric disorders in the National Comorbidity Survey. Arch Gen Psychiatry 1997;54(4):313-321. [PubMed: 9107147]

22. Kessler RC, McGonagle KA, Zhao S, Nelson CB, Hughes M, Eshleman S, Wittchen HU, Kendler KS. Lifetime and 12-month prevalence of DSM-III-R psychiatric disorders in the United States. Results from the National Comorbidity Survey. Arch Gen Psychiatry 1994;51(1):8-19. [PubMed: 8279933]

23. Haro JM, Arbabzadeh-Bouchez S, Brugha TS, de Girolamo G, Guyer ME, Jin R, Lepine JP, Mazzi F, Reneses B, Vilagut G, Sampson NA, Kessler RC. Concordance of the Composite International Diagnostic Interview Version 3.0 (CIDI 3.0) with standardized clinical assessments in the WHO World Mental Health surveys. Int J Methods Psychiatr Res 2006;15(4):167-180. [PubMed: 17266013]

24. Miller DT, Paschal DC, Gunter EW, Stroud PE, D’Angelo J. Determination of lead in blood using electrothermal atomisation atomic absorption spectrometry with a L'vov platform and matrix modifier. Analyst 1987;112(12):1701-1704. [PubMed: 3445938]

25. Parsons PJ, Slavin W. A rapid Zeeman graphite furnace atomic absorption spectrometric method for the determination of lead in blood. Spectrochimica Acta 1993;48B(6/7):925-939.

26. Centers for Disease Control and Prevention. NHANES laboratory/medical technologists procedures manual. [Accessed Feb. 6, 2009]. www.cdc.gov/nchs/data/nhanes/lab1-6.pdf

27. Pratt, LA.; Brody, DJ. NCHS Data Brief. U.S. Department of Helath and Human Services; Baltimore, MD: 2008. Depression in the United States household population, 2005-2006.

28. Bjelland I, Krokstad S, Mykletun A, Dahl AA, Tell GS, Tambs K, The HUNT study. Does a higher educational level protect against anxiety and depression? Soc Sci Med 2008;66(6):1334-1345. [PubMed: 18234406]

29. Wiesbeck GA, Kuhl HC, Yaldizli O, Wurst FM. Tobacco smoking and depression--results from the WHO/ISBRA study. Neuropsychobiology 2008;57(1-2):26-31. [PubMed: 18424908]

30. Aligne CA, Moss ME, Auinger P, Weitzman M. Association of pediatric dental caries with passive smoking. Jama 2003;289(10):1258-1264. [PubMed: 12633187] 
31. Hu H, Payton M, Korrick S, Aro A, Sparrow D, Weiss ST, Rotnitzky A, The normative aging study. Determinants of bone and blood lead levels among community-exposed middle-aged to elderly men. Am J Epidemiol 1996;144(8):749-759. [PubMed: 8857824]

32. Theppeang K, Glass TA, Bandeen-Roche K, Todd AC, Rohde CA, Schwartz BS. Gender and race/ ethnicity differences in lead dose biomarkers. Am J Public Health 2008;98(7):1248-1255. [PubMed: 18511728]

33. National Center for Health Statistics (NCHS). National Health and Nutrition Examination Survey Analytic Guidelines. [Accessed July 1, 2008]. http://www.cdc.gov/nchs/about/major/nhanes/nhanes2003-2004/analytical_guidelines.htm

34. National Centers for Health Statistics. National Health and Nutrition Examination Survey Analytic Guidelines. [Accessed July 1, 2008]. http://www.cdc.gov/nchs/data/nhanes/nhanes_general_guidelines_june_04.pdf

35. Lasley SM, Greenland RD, Minnema DJ, Michaelson IA. Influence of chronic inorganic lead exposure on regional dopamine and 5-hydroxytryptamine turnover in rat brain. Neurochem Res 1984;9(12):1675-1688. [PubMed: 6085136]

36. Minnema DJ, Greenland RD, Michaelson IA. Effect of in vitro inorganic lead on dopamine release from superfused rat striatal synaptosomes. Toxicol Appl Pharmacol 1986;84(2):400-411. [PubMed: 3715885]

37. Kala SV, Jadhav AL. Region-specific alterations in dopamine and serotonin metabolism in brains of rats exposed to low levels of lead. Neurotoxicology 1995;16(2):297-308. [PubMed: 7566689]

38. Dunlop BW, Nemeroff CB. The role of dopamine in the pathophysiology of depression. Arch Gen Psychiatry 2007;64(3):327-337. [PubMed: 17339521]

39. Neumeister A, Bain E, Nugent AC, Carson RE, Bonne O, Luckenbaugh DA, Eckelman W, Herscovitch P, Charney DS, Drevets WC. Reduced serotonin type 1A receptor binding in panic disorder. J Neurosci 2004;24(3):589-591. [PubMed: 14736842]

40. Kendler, KS.; Prescott, CA. Genes, environment, and psychopathology : understanding the causes of psychiatric and substance use disorders. Guilford Press; New York: 2006.

41. Rabinowitz MB. Toxicokinetics of bone lead. Environ Health Perspect 1991;91:33-37. [PubMed: 2040248]

42. Silbergeld EK, Schwartz J, Mahaffey K. Lead and osteoporosis: mobilization of lead from bone in postmenopausal women. Environ Res 1988;47(1):79-94. [PubMed: 3168967]

43. Flegal AR, Smith DR. Lead levels in preindustrial humans. N Engl J Med 1992;326(19):12931294. [PubMed: 1560812]

44. Bellinger DC, Bellinger AM. Childhood lead poisoning: the torturous path from science to policy. J Clin Invest 2006;116(4):853-857. [PubMed: 16585952]

45. van Os J, Jones P, Lewis G, Wadsworth M, Murray R. Developmental precursors of affective illness in a general population birth cohort. Arch Gen Psychiatry 1997;54(7):625-631. [PubMed: 9236546]

46. Braun JM, Froehlich TE, Daniels JL, Dietrich KN, Hornung R, Auinger P, Lanphear BP. Association of environmental toxicants and conduct disorder in U.S. children: NHANES 2001-2004. Environ Health Perspect 2008;116(7):956-962. [PubMed: 18629321]

47. Braun JM, Kahn RS, Froehlich T, Auinger P, Lanphear BP. Exposures to environmental toxicants and attention deficit hyperactivity disorder in U.S. children. Environ Health Perspect 2006;114(12):1904-1909. [PubMed: 17185283] 


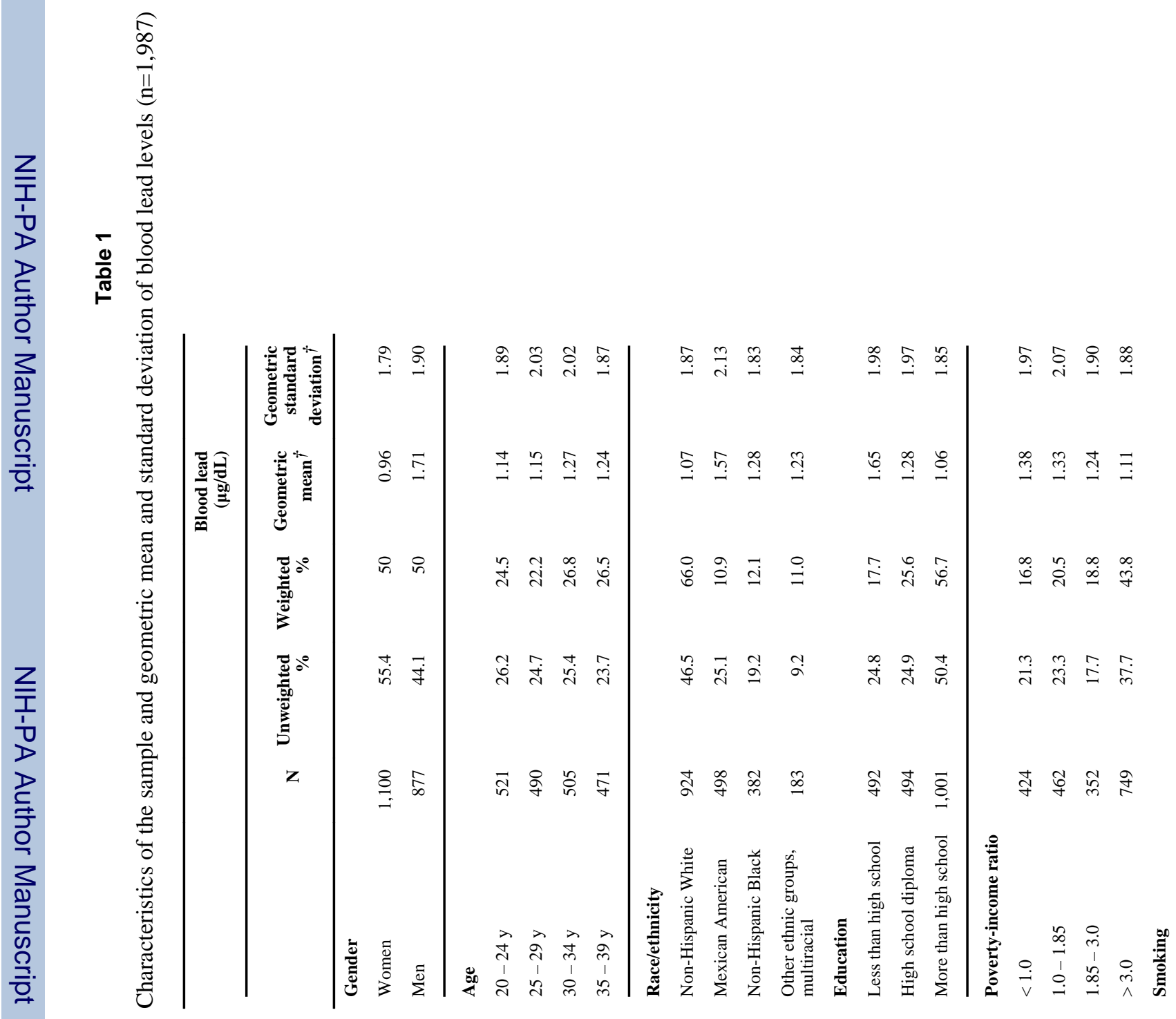
Arch Gen Psychiatry. Author manuscript; available in PMC 2010 December 1. 


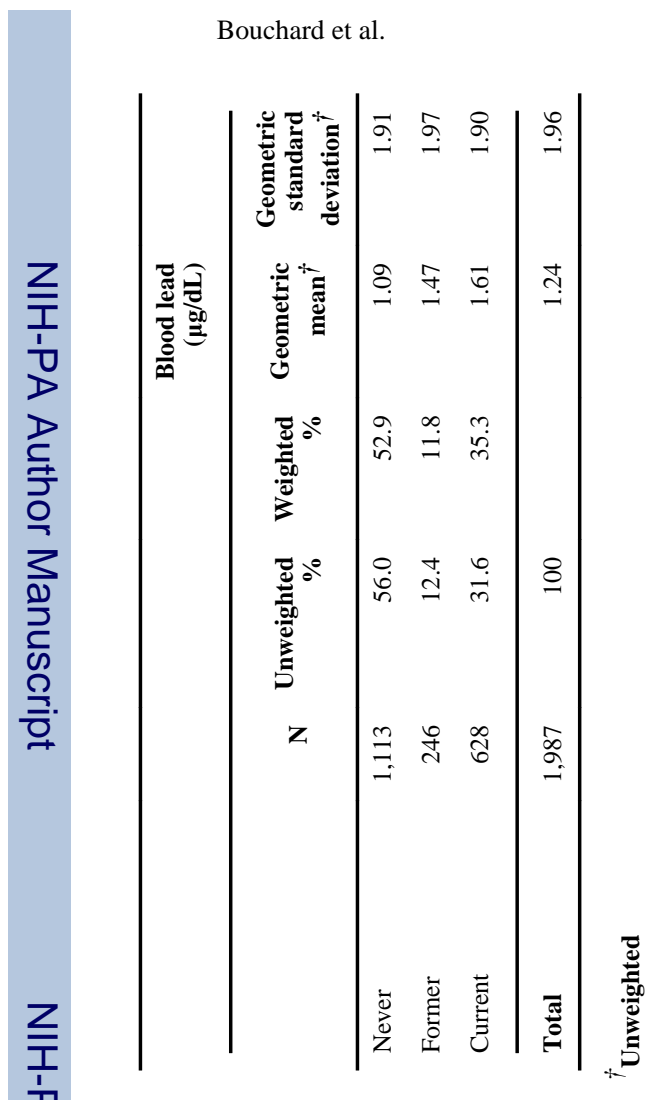

Page 13 


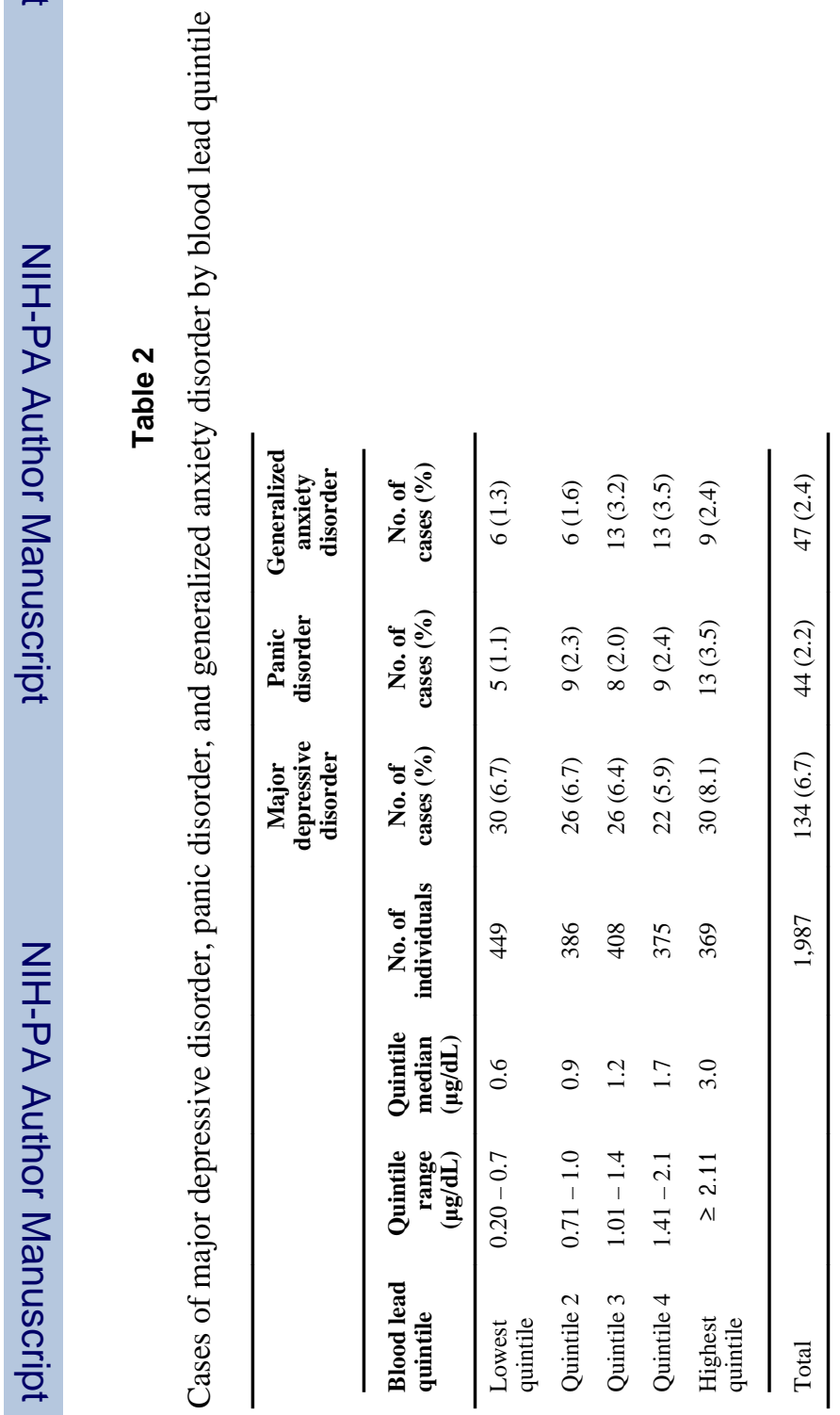




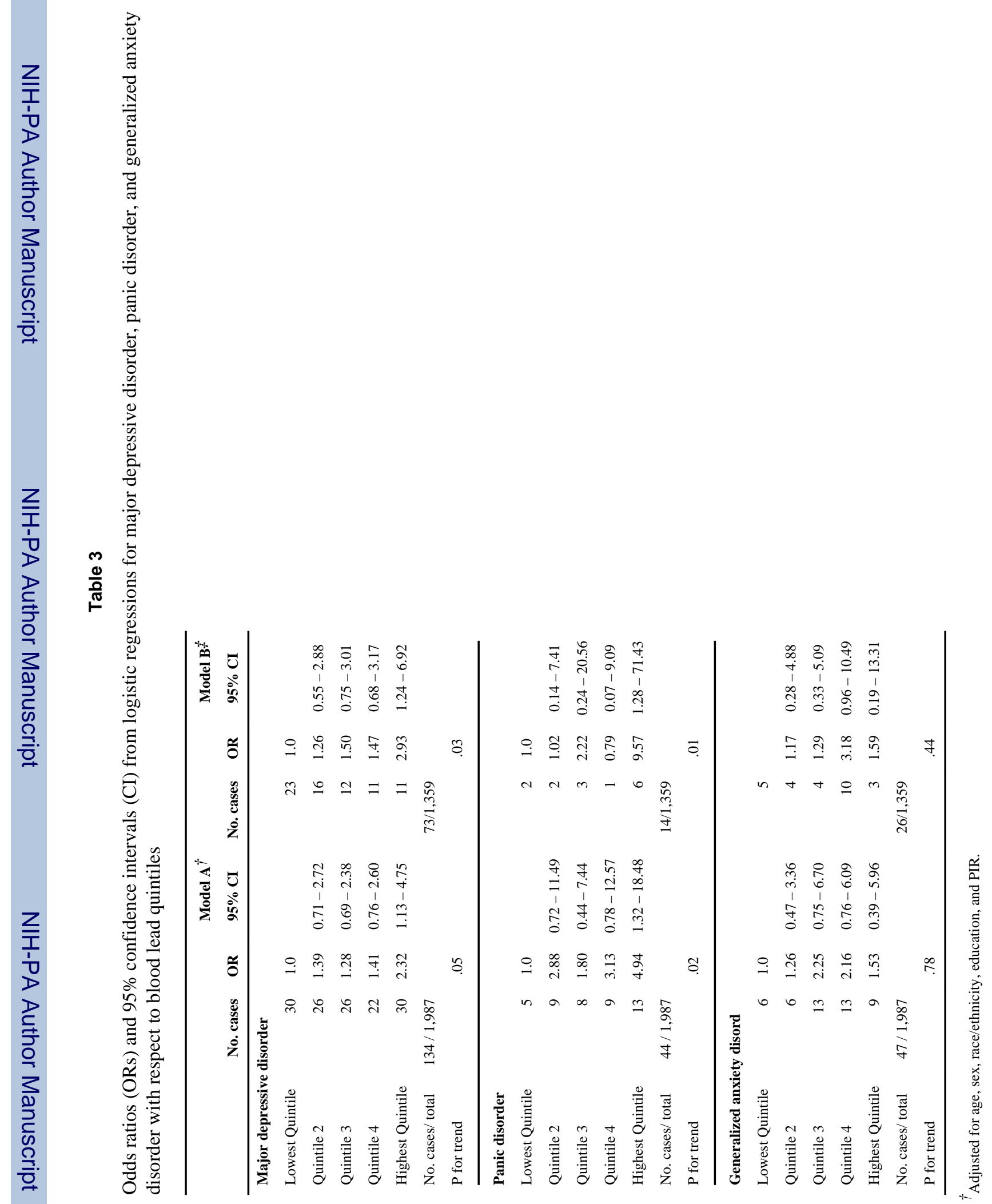


